Original Research Article

\title{
Drug utilization patterns of antibiotics in outpatient department of educare dental hospital at Malappuram, Kerala, India
}

\author{
Fayisa K.*, Anas P. P., Sudhakar A.
}

Department of Pharmacology, Educare Institute of Dental Sciences, Chattipparamba, Malappuram, Kerala, India

Received: 09 February 2019 Accepted: 03 March 2019

\section{*Correspondence to:}

Dr. Fayisa K.,

Email: fayisak1994@gmail.com

Copyright: (C) the author(s), publisher and licensee Medip Academy. This is an openaccess article distributed under the terms of the Creative Commons Attribution NonCommercial License, which permits unrestricted noncommercial use, distribution, and reproduction in any medium, provided the original work is properly cited.

\begin{abstract}
Background: Drug utilization studies aims to evaluate factors related to the prescribing, dispensing, administering and taking of medication, and its associated events. Antibiotic prescription by dental practitioners has an important impact on the rate of general antibiotic prescription use, and an attempt has been made to establish a surveillance system for the monitoring and control of the use of these drugs.

Methods: Retrospective record-based study was conducted at outpatient department at Educare Dental College and Hospital, Chattipparamba, Malappuram, Kerala. About 2802 prescriptions were screened, drugs prescribed were noted, tabulated and analysed.

Results: Total no. of prescriptions 2802, total no. of antibiotics prescribed 2916, average no of antibiotics per prescription 1.04. Out of antibiotics prescribed $72 \%$ were monotherapy and $28 \%$ were fixed dose combination. Among antibiotics beta lactam antibiotics were commonly prescribed followed by nitroimidazoles and macrolides.

Conclusions: The study was conducted to analyze the drug utilization pattern in outpatient department at dental hospital. Most of prescription were rational, both monotherapy and polypharmacy were practiced. Safer drug with less adverse effect profile were considered. Among the antibiotic amoxicillin was the commonest.
\end{abstract}

Keywords: Antibiotics, Drug utilization, Dentistry, Outpatient department, Penicillins, Prescription

\section{INTRODUCTION}

Drug utilization research was defined by World Health Organization in 1977 as "the marketing, distribution, prescription and use of drugs in a society, with special emphasis on the resulting medical, social and economic consequences. ${ }^{1}$ Drug utilization research focuses on various medical, social and economic aspects of drug use. ${ }^{2}$ Drug utilization studies aims to evaluate factors related to the prescribing, dispensing, administering and taking of medication, and its associated events. ${ }^{3}$ Drug utilization patterns are powerful, tools to ascertain role of drugs in medical practice. They create a sound and economic basis for health care and outpatient clinics deliver therapeutic service to large segments of the patients. Assessment of prescribing pattern in these important medical care facilities is of obvious relevance to identify problems regarding rational use and to propose interventions. ${ }^{4}$

Drug utilization is important for every drug but especially for antibiotics as they are widely used drugs in health care and their excessive and inappropriate use in hospitals, health care facilities and community contributes to the development of bacterial resistance. ${ }^{5}$ Drug utilization study is a component of medical audit that does monitoring and evaluation of the drug prescribing patterns and suggests necessary modifications in prescribing practices 
to achieve rational therapeutic practice as well as cost effective health care.

Antimicrobial drugs (AMDs) are among the most commonly prescribed therapeutic agents, accounting for $30-50 \%$ of drug prescriptions. ${ }^{6}$ Higher incidence of infections in adults leads to higher use of AMDs, contributing to an overall increase in healthcare costs, as well as, potentially severe adverse drug reactions. ${ }^{7}$ Antibiotics are possibly the most vital advancement in the history of medicine and undoubtedly; they are among medicine's most prevailing sector. Infrequent uses of antibiotics increase the chances of the bacterial resistance. ${ }^{8,9}$ The detailed knowledge of AMD pattern is important before executing these policies into practice. Hence this study was undertaken to perform drug utilization evaluation and access prescribing trends of antibiotics in Educare Dental hospital Chattiparamba, Kerala.

\section{METHODS}

This retrospective study was carried out by collecting prescriptions of the patients attending outpatient department of Educare Dental College after securing Institutional Ethical Committee permission to assess the prescribing patterns of drugs. Study was carried out for a period of 3 months from September to November 2018by using the medication order from July 2018 to September 2018. Total 2802 prescriptions containing various drugs were collected from the hospital record section for the study. All the antibiotics drugs prescribed were noted including dose, route, dosage form, frequency of administration, indications for prescription and duration of therapy, number of drugs prescribed from Essential Drug list were also noted as per WHO/International Network of Rational Use of Drugs (INRUD) drug use indicators. In this study, the data were analyzed using Microsoft ${ }^{\circledR}$ Excel software 2007, USA. The results are presented using descriptive statistics, such as the frequency of distribution 10 .

\section{Inclusion criteria}

- Medication orders of dental outpatients were analyzed for a period of 3 months.

- Patients of any age group.

\section{Exclusion criteria}

- Ineligible and incomplete prescription order as per International Rational use of Drug (INRUD).

- Cases of oral cancer were excluded from the study.

\section{RESULTS}

\section{Prescription pattern}

Prescription pattern of the 2802 prescriptions were analyzed in which total 5952 drugs used for the treatment of the patients. The total number of medications per prescription was of 1 to 4 .

- $\quad$ Total no. of prescriptions $=2802$

- Total no. of drugs prescribed= 5952

- Avg. no. of drugs prescribed= 2.1

- Total no. of antibiotics prescribed $=2916$

- Avg no. of antibiotics per prescription= 1.04

The majority of the patients attending in the hospital were female $(57.6 \%)$. The age of the patients ranged from 5 to 63 years with an average of years where almost half of the patients highest prevalence of diseases was above 25 years old as seen from Figure 1.

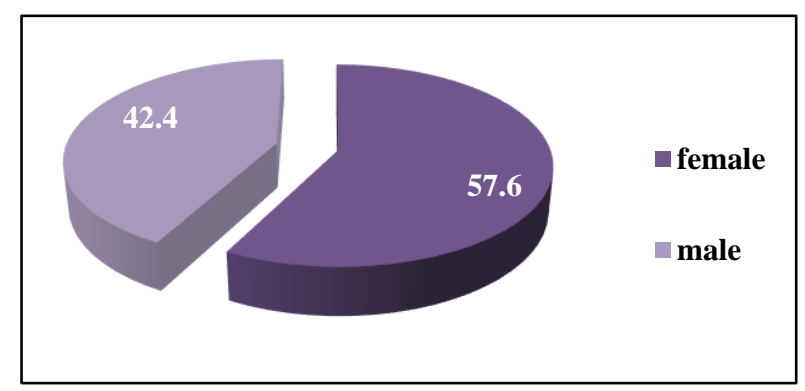

Figure 1: Gender based distribution.

The total number of medications per prescription was of 1 to 4. Total number of antibiotics prescribed was 2916. Average no antibiotics per prescription 1.04. Out of antibiotics prescribed $72 \%$ were monotherapy and $28 \%$ were fixed dose combination as seen in Figure 2.

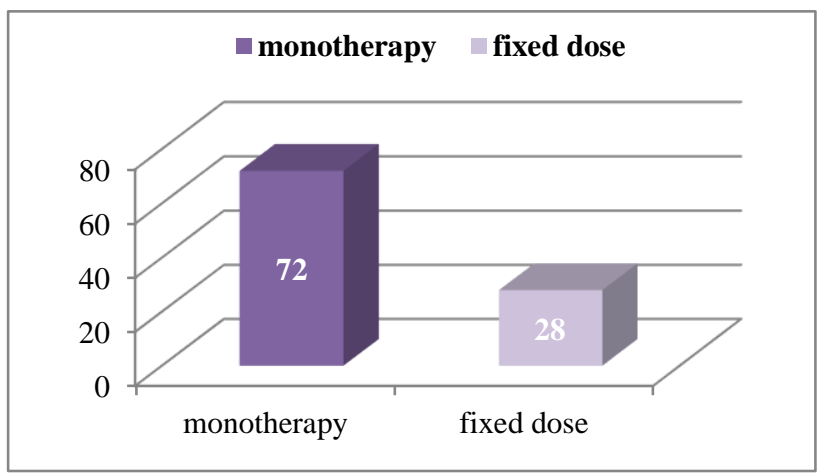

Figure 2: Percentage of antibiotics prescription pattern in outpatient department.

Study also revealed that the percentage of antibiotics prescribed from penicillins class was $81.88 \%$. Percentage of antibiotics prescribed from nitroimidazole class was $17.69 \%$ and percentage of antibiotics prescribed from microcline class was $0.43 \%$ as seen as Figure 3.

The total number of antibiotic prescribed was 2916. Total number of antibiotics given by fixed dose combination was 812 whereas 2104 of the total antibiotics was given as monotherapy. The percentage of drugs prescribed in type of monotherapy was $72 \%$ and fixed dose combination was 
$28 \%$, majority of antibiotics prescribed by monotherapy as seen as Table 1.

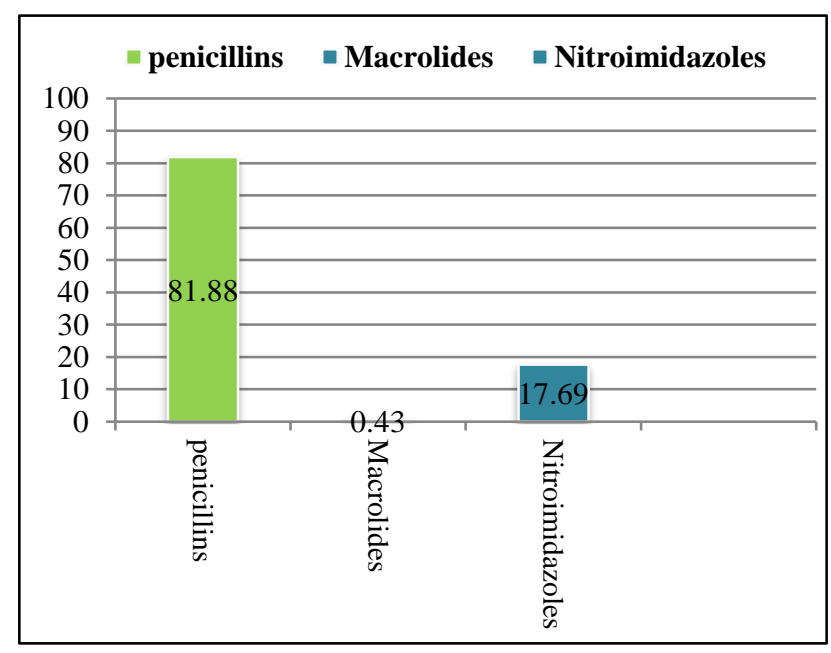

Figure 3: Percentage of antibiotic classes of prescription in outpatient department.

Table 1: Prescription pattern of antibiotics in outpatient department.

\begin{tabular}{|lll|}
\hline $\begin{array}{l}\text { Mode of } \\
\text { therapy }\end{array}$ & No. of antibiotic & $\%$ of antibiotics \\
\hline Monotherapy & 2104 & $72 \%$ \\
\hline FDC & 812 & $28 \%$ \\
\hline Total & 2916 & $100 \%$ \\
\hline
\end{tabular}

Table 2: Prescribed antibiotic classes in outpatient department.

\begin{tabular}{|lll|}
\hline $\begin{array}{l}\text { Name of drugs } \\
\text { Penicillins }\end{array}$ & $\begin{array}{l}\text { No. of } \\
\text { antibiotic }\end{array}$ & $\begin{array}{l}\text { \% of } \\
\text { antibiotics }\end{array}$ \\
\hline Amoxicillin & 1576 & 54.04 \\
\hline $\begin{array}{l}\text { Amoxicillin+ } \\
\text { clavulanic acid }\end{array}$ & 812 & 27.84 \\
\hline Macrolides & & \\
\hline Azithromycin & 12 & 0.43 \\
\hline Nitroimidazole & & \\
\hline Metronidazole & 516 & 17.69 \\
\hline
\end{tabular}

The number of encounters with antibiotics was $2916 / 5952$ (48.99\%), in which penicillins were the most common group of antibiotics prescribed. Of the various class of antibiotics administered penicillin was the commonest group of antibiotics prescribed (amoxicillin- 54.04\% and amoxicillin + clavulanic acid- 27.84\%) followed by nitroimidazole (17.695) and macrolides (azithromycin$0.43 \%$ ) as seen in Table 2.

\section{DISCUSSION}

Proper diagnosis of a dental condition and its management with medicine and dental procedure plays the pivotal role in dental care. This study shows that the entire patient visiting outpatient department of Educare Dental Hospital received the dental therapy. ${ }^{11}$ Prescription pattern of the 2802 prescriptions, there were total 5952 drugs used for the treatment of the patients. The majority of the patients attending in the hospital were female $(57.6 \%)$. The age of the patients ranged from 5 to 63 years with an average of years where almost half of the patients highest prevalence of diseases was above 23 years old. The total number of medications per prescription was of 1 to 4 . Total number of antibiotics prescribed was 2916. Average no antibiotics per prescription 1.04. Out of antibiotics prescribed $72 \%$ were monotherapy and $28 \%$ were fixed dose combination. In the present study, amoxicillin was the most commonly prescribed antibiotic followed by amoxicillin and clavulanic acid combination and metronidazole

Penicillins and fluoroquinolone groups were selected to combat the gram positive and gram-negative organisms, and nitro-imidazole group of drugs were co-administered, Metronidazole has been found to be very effective against anaerobes but not against facultative anearobic bacteria. Hence it become necessary for it to be used in conjunction with other agents, more over if within 48 hours the patients are not responding to penicillin alone one can consider adding metronidazole to the existing drug regimen. Azhithromycin does not find any role in oral infection because about $80 \%$ oral streptococci develop resistance to macrolides after a single cause. ${ }^{12}$ So it was concluded that majority of dental cases are reported related to dental infections and Antibiotics were prescribed for dental abscesses, post root canal treatment, post dental extraction and after most minor surgical procedures. ${ }^{13}$ Rational antibiotic use is thus required in dental and oral clinical practice, to ensure maximum efficacy while at the same time minimizing the side effects and the appearance of resistances. ${ }^{14,15}$

The limitation of this present study is that the data are manually collected from the patients' medical records. In general, based on our main findings, authors recommend improving the system used for data recording, management and maintenance, which may result in a better and more efficient drug prescription monitoring system in primary dental care. Additionally, we recommend the development of treatment guidelines and protocols, with the main objective of religious use of antibiotics.

\section{CONCLUSION}

The study was shown to analyze the drug utilization pattern in outpatient department at dental hospital. Most of prescription were rational both monotherapy and polypharmacy where practiced. Safer drug with less adverse effect profile were considered. Among the antibiotic amoxicillin were commonest. 


\section{ACKNOWLEDGEMENTS}

Authors would like to sincerely thank Dr. Indushekar, Principal, Educare Institute of Dental Sciences, Chattiparamba, Malappuram, Kerala for his guidance and valuable suggestions during the course of this study.

Funding: No funding sources

Conflict of interest: None declared

Ethical approval: The study was approved by the Institutional Ethics Committee

\section{REFERENCES}

1. Shalini S, Ravichandran V, Mohanty BK, Dhanaraj SK, Saraswathi K. Drug Utelization Studies-An Overview. Int $\mathbf{J}$ Pharmaceut Sci Nanotechnol. 2010;3(1):803-10.

2. Wettermark B, Elseviers M, Almarsdottir AB. Drug Utilization Research: Methods and Applications, John Wiley \& Sons, Ltd.2016;1:3-12.

3. Pratiti, Pratyay PD. Drug utilization Pattern in oral medicine Department of Saveetha Dental college, Tamilnadu, India. National J Med Res. 2015;5(1):271-4.

4. Jayanthi MK, Naidu SV. Drug utilization Pattern and pharmacoeconomic study in paediatric Dentistry at a tertiary hospital. Int $\mathbf{J}$ Pharma Pharmaceut Sci. 2013;6(2):70-2.

5. Shrikala B, Kranthi K. A prospective study on evaluation of antibiotic prescription practices in an intensive care unit of a tertiary care hospital. J Clin Diagn Res. 2010;4(6):3387-91.

6. van Houten MA, Luinge K, Laseur M, Kimpen JL. Antibiotic utilisation for hospitalised paediatric patients. Int J Antimicrob Agents. 1998;10(2):161-4.

7. Stallworth LE, Fick DM, Ownby DR, Waller JL. Antibiotic use in children who have asthma: results of retrospective database analysis. J Managed Care Pharma. 2005;11(8):657-62.
8. Bithi SS, Khan MM, Khan AU. Drug utilization study in orthopaedic units: Antibiotics prescribed in hospital out-patients in Dhaka, Bangladesh. Int Curr Pharmaceut J. 2014;3(9):318-21.

9. Takhar P, Yadav S, Dua S, Mahant S. Investigation of antibiotic usage pattern: A prospective drug utilization review. Der. Pharmacia. Lettre. 2011;3:301-6.

10. Ahmed MM, Harsoor A, Nizami S. A prospective study of drug utilization in patients attending ophthalmology outpatient department at KBN teaching and general hospital of Gulbarga, India. Int $\mathbf{J}$ Basic Clin Pharmacol. 2018;7(8):1-5.

11. Paudel KR, Sah NK, Jaiswal AK. Prevalence of pharmacotherapy in department of paediatric dentistry. Kathmandu Uni Med J. 2009;8(30):190-4.

12. Kaul R, Angrish P, Jain P, Saha S, Sengupta AV, Mukherjee S. A Survey on the Use of Antibiotics among the Dentists of Kolkata, West Bengal, India. Int J Clin Pediatr Dentistr. 2018 Mar;11(2):122-7.

13. Sharma D, Reeta KH, Badyal DK, Garg SK, Bhargava VK. Antimicrobial prescribing pattern in an Indian tertiary hospital. Indian J Physiol Pharmacol. 1998;42 (4):533-7.

14. Roda RP, Bagan JV, Bielsa JS, Pastor EC. Antibiotic use in dental practice. A review. Med Oral Patol Oral Cir Bucal. 2007;12(3):186-92.

15. Stanulović M, Jakovljević V, Rončević N. Drug utilization in paediatrics: non-medical factors affecting decision making by prescribers. Eur J Clin Pharmacol. 1984;27(2):237-41.

Cite this article as: Fayisa K, Anas PP, Sudhakar A. Drug utilization patterns of antibiotics in outpatient department of educare dental hospital at Malappuram, Kerala, India. Int J Basic Clin Pharmacol 2019;8:930-3. 